\title{
Numerical analysis of beam rail bridges with random track irregularities
}

\author{
Monika Podwórna ${ }^{1, *}$ \\ ${ }^{1}$ Wroclaw University of Science and Technology, Faculty of Civil Engineering, 50-370 Wroclaw, \\ Wyb. Wyspianskiego 27, Poland
}

\begin{abstract}
The study focuses on dynamic analysis of composite bridge / track structure / train systems (BTT systems) with random vertical track irregularities taken into consideration. The paper presents the results of numerical analysis of advanced virtual models of series-of-types of singlespan simply-supported railway steel-concrete bridges (SCB) with symmetric platforms, located on lines with the ballasted track structure adapted to traffic of high-speed trains.
\end{abstract}

\section{Introduction}

Moving-load as a dynamic problem is very common in science papers because of many structures subjected to loads which move in space, for example Fryba's monograph described a lot of moving-load problems and their analytic solutions [1]. Transportation systems play a key role in modern societies - social and economic development requires the fast and efficient mobility. In recent decades, train operating speeds have been significantly increased. The literature studies confirmed that one of the main factors affecting the dynamic response of railway engineering structures are irregularities in the railway surface - track irregularities [2-12]. The irregularities are due to track formation technology, contemporary mechanical maintenance, soil settlement and other factors. Experimental measurements and modelling of track irregularities are considered in a number of papers, e.g. [13-14]. A common model of railway track vertical irregularities is a stationary and ergodic Gaussian process in space $[4,10,11,12]$.

\section{Description of modelling and simulation of BTT systems}

\subsection{Description of series-of-types of railway bridges (SCB)}

The detailed description of design the SCB (steel-concrete bridges) series-of-types of railway bridges are presented in Ref. [15]. The bridge series-of-types consists of five objects with codes and basic geometric parameters listed in Table 1 , where $L[\mathrm{~m}]-$ theoretical span length, $L_{\mathrm{T}}[\mathrm{m}]$ - total span length, $\mathrm{H}[\mathrm{m}]$ - structural height. They are a

* Corresponding author: monika.podworna@pwr.edu.pl 
single-span simply-supported railway composite (steel - concrete) bridges, with a symmetric platform, a ballasted track structure adapted for high-speed trains.

Table 1. Codes and basic geometric parameters of bridges forming SCB series-of-types.

\begin{tabular}{cccccc}
\hline Bridge code & SCB-15 & SCB-18 & SCB-21 & SCB-24 & SCB-27 \\
\hline$L[\mathrm{~m}]$ & 15.00 & 18.00 & 21.00 & 24.00 & 27.00 \\
$L_{\mathrm{T}}[\mathrm{m}]$ & 15.80 & 18.80 & 21.80 & 24.80 & 27.80 \\
$\mathrm{H}[\mathrm{m}]$ & 1.82 & 1.97 & 2.12 & 2.27 & 2.42 \\
\hline
\end{tabular}

\subsection{Description of mathematical and numerical modelling of BTT systems}

The theory of advanced physical and mathematical modelling of BTT (bridge / track structure / train) systems has been developed by Podworna and Klasztorny in 2014, [16]. In the physical and numerical modelling, the following main assumptions were adopted:

- There is considered a finitely long deformable track with continuously welded rails including the out-of-transition zones, the transition zones and the bridge zone.

- The bridge superstructure is reflected by a simply-supported stepwise viscoelastic prismatic beam, deformable in flexure, symmetrical relative to the bridge midspan.

- The operating and the side rails are viscoelastic prismatic beams deformable in flexure.

- The rail-sleeper fasteners are viscoelastic elements with non-linear elastic characteristic.

- The sleepers vibrate vertically and are modelled as concentrated masses.

- The crushed stone ballast is modelled as a set of vertical viscoelastic constraints with non-linear elastic characteristic. The model includes possibility of detachment of sleepers from the ballast. The lumped ballast model is used.

- The track bed (subsoil) is a linearly viscoelastic layer modelled discretely.

- The approach slabs are modelled as viscoelastic prismatic beams deformable in flexure.

- $\quad$ There are random vertical track irregularities.

- The rail-vehicles form a high-speed ICE-3 (Inter City Express) German train. Each vehicle has two independent two-axle bogies. The planar Matsuura model of railvehicle is developed via incorporating non-linear one-sided contact springs at wheel set - rail contacts.

- The vehicle model includes the Hertz contact nonlinear stiffness between moving wheels and rail heads (developed in 1880s [17]), and potential detachment of moving wheels from rail heads.

- Micro separations and impacts of moving wheel sets in reference to the main rails are taken into consideration.

- A train operating speed is constant and ranges from 30 to $300 \mathrm{~km} / \mathrm{h}$. A velocity of 30 $\mathrm{km} / \mathrm{h}$ is treated as relevant to the quasi-static passage of train.

- Vibrations of BTT system are physically nonlinear and geometrically linear.

The physical model of BTT subsystem is presented in Fig. 1. A constant sleeper spacing $d$ is used to discretise these subsystem. Discretization of beams modelling operating and side rails, approach slabs and the bridge superstructure uses classic beam finite elements deformable in flexure, with 4DOF and length $d[16]$. 


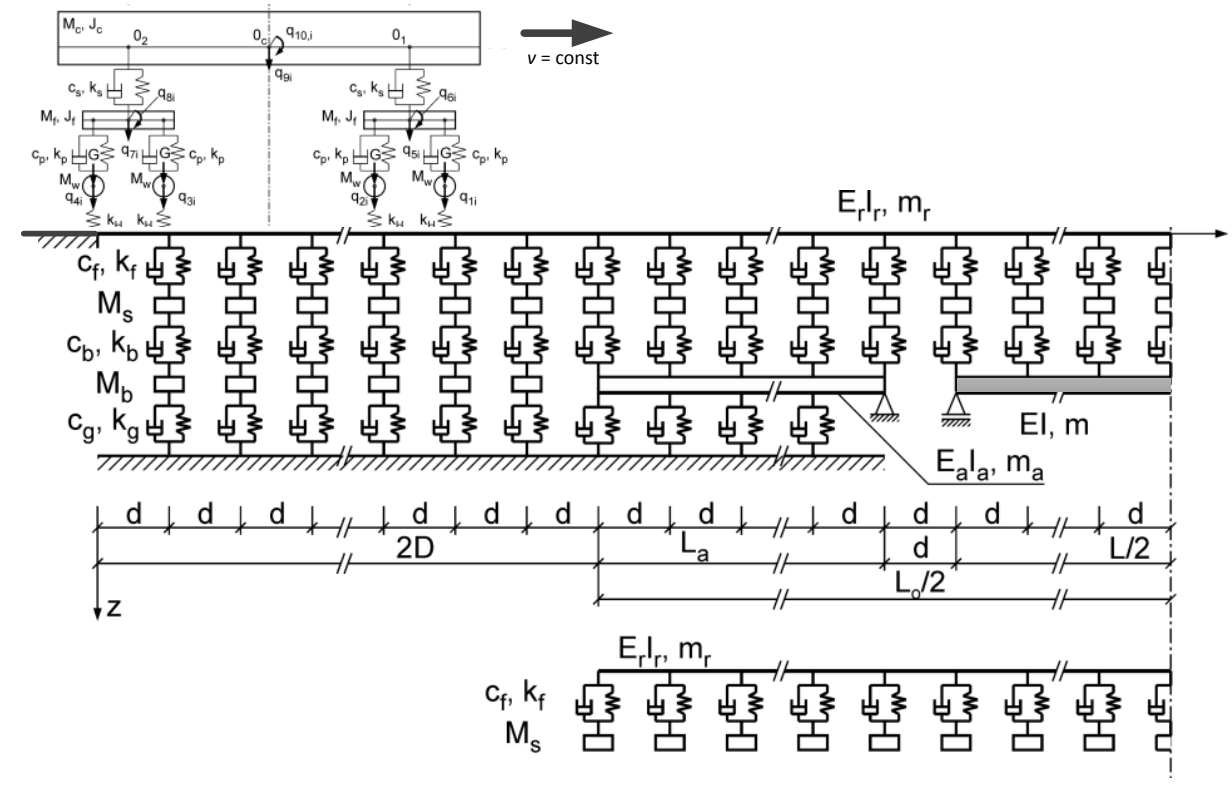

Fig. 1. Physical model of track structure / bridge subsystem (left part)

A BTT system is composed of the following inertial subsystems (Fig.1): BS - bridge superstructure, LAS - left approach slab, RAS - right approach slab, LB - left ballast-bed, $\mathrm{RB}$ - right ballast-bed, $\mathrm{SL}$-sleepers, $\mathrm{OR}$ - operating rails, $\mathrm{SR}$ - side rails, $\mathrm{RV} i, i=$ $1,2, \ldots, N_{v}$ - railway vehicles. These subsystems are subjected to relevant subsets of vertical interaction forces, carried by elastic and viscoelastic physically linear and nonlinear constraints. Using the Lagrange equations and the internal assembling, linear matrix equations of motion of individual subsystems are obtained with the generalized load vectors stored in the implicit form, [16]:

where:

$$
\begin{gathered}
\mathbf{B} \ddot{\mathbf{q}}+\mathbf{C} \dot{\mathbf{q}}+\mathbf{K q}=\mathbf{F} \\
\mathbf{B}_{l a} \ddot{\mathbf{q}}_{l a}+\mathbf{C}_{l a} \dot{\mathbf{q}}_{l a}+\mathbf{K}_{l a} \mathbf{q}_{l a}=\mathbf{F}_{l a} \\
\mathbf{B}_{r a} \ddot{\mathbf{q}}_{r a}+\mathbf{C}_{r a} \dot{\mathbf{q}}_{r a}+\mathbf{K}_{r a} \mathbf{q}_{r a}=\mathbf{F}_{r a} \\
\left\{\mathbf{M}_{b}\right\} \ddot{\mathbf{q}}_{l b}=\mathbf{F}_{l b} \\
\left\{\mathbf{M}_{b}\right\} \ddot{\mathbf{q}}_{r b}=\mathbf{F}_{r b} \\
\left\{\mathbf{M}_{s}\right\} \ddot{\mathbf{q}}_{s}=\mathbf{R}_{f}-\mathbf{R}_{b} \\
\mathbf{B}_{r} \ddot{\mathbf{q}}_{r}+\mathbf{C}_{r} \dot{\mathbf{q}}_{r}+\mathbf{K}_{r} \mathbf{q}_{r}=\mathbf{F}_{r} \\
\mathbf{B}_{s r} \ddot{\mathbf{q}}_{s r}+\mathbf{C}_{s r} \dot{\mathbf{q}}_{s r}+\mathbf{K}_{s r} \mathbf{q}_{s r}=\mathbf{F}_{s r} \\
\mathbf{B}_{i} \ddot{\mathbf{q}}_{i}=\mathbf{F}_{i}, \quad \mathrm{i}=1,2, \ldots, N_{v}
\end{gathered}
$$

$\mathbf{q}(t), \mathbf{q}_{l a}(t), \mathbf{q}_{r a}(t), \mathbf{q}_{l b}(t), \mathbf{q}_{r b}(t), \mathbf{q}_{s}(t), \mathbf{q}_{r}(t), \mathbf{q}_{s r}(t), \mathbf{q}_{i}(t), i=1,2, \ldots, N_{v} \quad-$ vectors of generalised coordinates in reference to BS, LAS, RAS, LB, RB, SL, OR, SR, RV subsystems, respectively;

$\mathbf{B}, \mathbf{C}, \mathbf{K}, \mathbf{B}_{l a}, \mathbf{C}_{l a}, \mathbf{K}_{l a}, \mathbf{B}_{r a}, \mathbf{C}_{r a}, \mathbf{K}_{r a}, \mathbf{B}_{r}, \mathbf{C}_{r}, \mathbf{K}_{r}, \mathbf{B}_{s r}, \mathbf{C}_{s r}, \mathbf{K}_{s r} \quad$ - mass, damping and stiffness matrices for BS, LAS, RAS, OR and SR subsystems, respectively;

$\left\{\mathbf{M}_{b}\right\},\left\{\mathbf{M}_{s}\right\}$ - mass matrix for left and right ballast-bed, sleepers subsystems, respectively;

$\mathbf{R}_{f}, \mathbf{R}_{s f}, \mathbf{R}_{b}, \mathbf{R}_{g}$ - vectors of interaction forces transmitted by fasteners in operating and side rails, ballast bed, subgrade subsystems, respectively; 
$\mathbf{F}\left(\mathbf{R}_{b}\right), \mathbf{F}_{l a}\left(\mathbf{R}_{b}, \mathbf{R}_{g}\right), \mathbf{F}_{r a}\left(\mathbf{R}_{b}, \mathbf{R}_{g}\right), \mathbf{F}_{l b}\left(\mathbf{R}_{b}, \mathbf{R}_{g}\right), \mathbf{F}_{r b}\left(\mathbf{R}_{b}, \mathbf{R}_{g}\right), \mathbf{F}_{r}\left(\mathbf{R}_{f}, \mathbf{R}_{w i}\right), \mathbf{F}_{s r}\left(\mathbf{R}_{s f}\right)-$ generalised load vector in implicit form, related to BS, LAS and RAS, LB and RB, OR and SR subsystems, respectively;

$\mathbf{R}_{w i}$ - vector of moving pressure forces of $i^{\text {th }}$ vehicle wheel sets acting on rails;

$\mathbf{B}_{i}$ - mass matrix for $i^{\text {th }}$ rail-vehicle;

$\mathbf{R}_{i}=\operatorname{col}\left(R_{1 i} R_{2 i} \ldots R_{10, i}\right)-$ vector of vertical interactions transmitted by $1^{\text {st }}$ and $2^{\text {nd }}$ stage suspensions of $i^{\mathrm{th}}$ vehicle;

G - generalised load vector reflecting static pressures of wheel sets onto rails;

$\mathbf{F}_{i}\left(\mathbf{R}_{i}, \mathbf{G}\right)$ - generalised load vector in implicit form, related to $\mathrm{RV} i, i=1,2, \ldots, N_{v}$ subsystem;

$\left({ }^{\circ}\right)=d / d t-$ differentiation with respect to $t$.

Detailed formulae defining matrices and vectors in Eqs. (1) are given in Ref. [16].

\subsection{Modelling of wheel - rail contact stiffness and random vertical track irregularities}

The modelling of wheel - rail contact stiffness according to the Hertz theory is presented by e.g. Lei and Noda, [12] - the wheel - rail contact is considered as two elastic contact cylinders perpendicular to each other. The relative vertical shortening between the wheel and the rail is calculated from the formula

$$
u_{H}=R_{1}^{2 / 3} / k_{H}
$$

where: $u_{H}$ - vertical shortening, $k_{H}$ - contact stiffness coefficient, $R_{1}=0.5 R-$ half of the interaction force per wheel set.

Only the vertical profile is taken into consideration, short wavelength corrugation irregularities in rail are neglected. The profile is characterized by the one-sided power spectral density function (PSD), which corresponds to line grades 1 to 6 defined in the American Railway Standard was elaborated by the Federal Railroad Administration (FRA), USA. The most common definition of the PSD function $S_{r r}(\Omega)$ is presented by Fryba, [1]:

$$
S_{r r}(\Omega)=k A \frac{\Omega_{c}^{2}}{\left(\Omega^{2}+\Omega_{c}^{2}\right) \Omega^{2}} \quad\left[\frac{\mathrm{mm}^{2} \mathrm{~m}}{\mathrm{rad}}\right]
$$

where: $S_{r r}(\Omega)$ - one-sided PSD function(a stationary and ergodic Gaussian process in space), $k=0.25, \Omega_{c}=0.8245[\mathrm{rad} / \mathrm{m}]$. The coefficient $A\left[\mathrm{~mm}^{2} \mathrm{rad} / \mathrm{m}\right]$ is specified for FRA line grades 1-6. Only two lines are considered in this study (grades 5 with $A=20.95-$ the symbol TI5 and 4 with $A=53.76$ - the symbol TI4).

Random samples of track irregularity vertical profile are generated with the MonteCarlo method, [1]

$$
r(x)=2 \sum_{i=1}^{N_{r}} \sqrt{S_{r r}\left(\Omega_{\mathrm{i}}\right) \Delta \Omega} \cos \left(\Omega_{i} x+\varphi_{i}\right) \quad[\mathrm{mm}]
$$

where:

$\Delta \Omega=\frac{1}{\mathrm{~N}_{\mathrm{r}}}\left(\Omega_{\max }-\Omega_{\min }\right)-$ frequency increment;

$\Omega_{\min }=\frac{2 \pi}{L_{r, \max }}, \quad \Omega_{\max }=\frac{2 \pi}{L_{r, \min }}-$ lower and upper limits of spatial frequency;

$L_{r, \text { min }}, L_{r, \text { max }}-$ lower and upper limits of wavelength $\left(L_{r, \min }=0.10 \mathrm{~m}, L_{r, \max }=\right.$

$70.00 \mathrm{~m}$ are assumed to be adequate [18])

$\Omega_{i}=\Omega_{\min }+(\mathrm{i}-0.5) \Delta \Omega-$ discrete frequency; 
$\varphi_{i} \quad$ random phase angle uniformly distributed over $[0,2 \pi][\mathrm{rad}]$ interval and independent for $i=1,2, \ldots, N_{r}$;

$N_{r}$ - total number of frequency increments in $\left[\Omega_{\min }, \Omega_{\max }\right] ;\left(N_{r}=100\right.$ is assumed to be adequate [18])

\section{Numerical analysis of BTT systems}

The study presents the impact factors in the longitudinal normal stress in the bottom fibres of main steel beams at the midspan which were obtained in dynamic analysis of the BTT systems. Also there is a comparison with the impact factors in the vertical deflection at midspan of SCB. The impact factors are calculated from the well-known classic formulae, i.e.

$$
\varphi_{w}(0.5 L)=\frac{\max _{t} w(0.5 L, t)}{\max _{t} w_{S}(0.5 L, t)}, \varphi_{\sigma}(0.5 L)=\frac{\max _{t} \sigma(0.5 L, t)}{\max _{t} \sigma_{S}(0.5 L, t)}
$$

where:

$w(0.5 L, t)$ - dynamic vertical deflection, simulated with or without random track irregularities for the selected resonant and extra-resonant train speeds;

$w_{s}(0.5 L, t)$ - quasi-static vertical deflection, simulated for the train speed $v=30 \mathrm{~km} / \mathrm{h}$ and for the smooth track;

$\sigma(0.5 L, t)$ - dynamic longitudinal normal stress, simulated with or without random track irregularities for the selected resonant and extra-resonant train speeds;

$\sigma_{s}(0.5 L, t)$ - quasi-static longitudinal normal stress, simulated for the train speed $v=30 \mathrm{~km} / \mathrm{h}$ and for the smooth track.

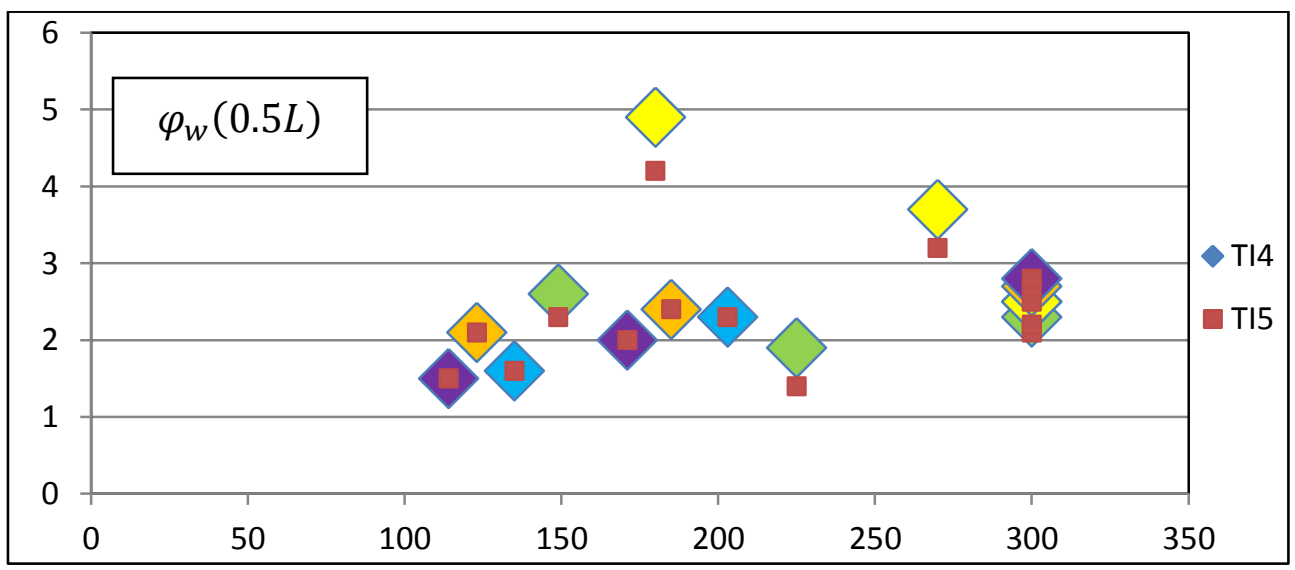

Fig. 2. Chart deflection impact factors of the SCB bridges depending on the speed. 


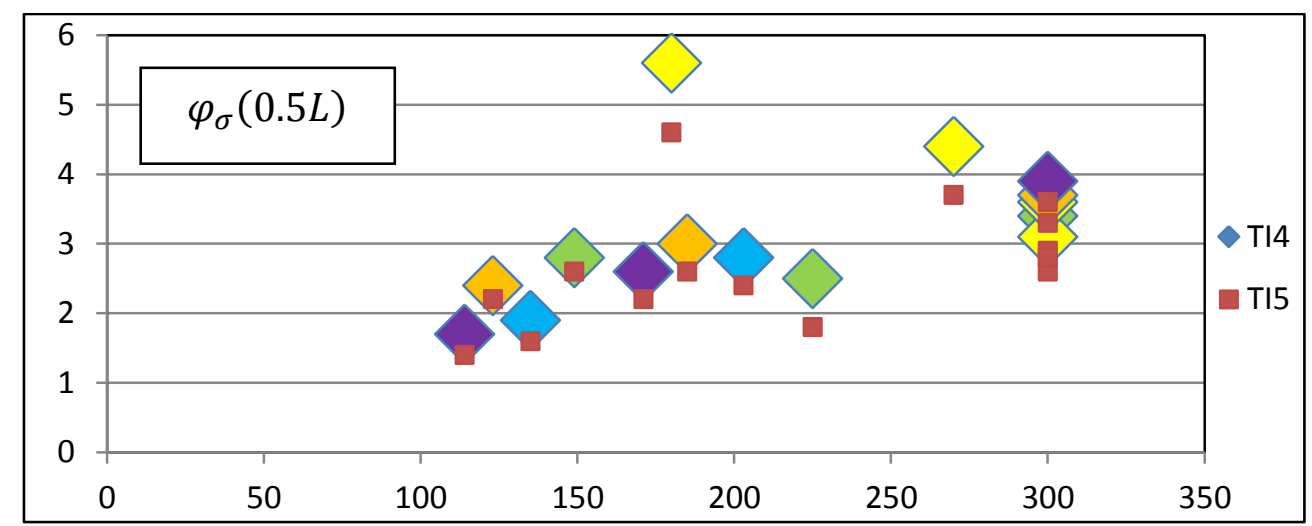

Fig. 3. Chart longitudinal normal stress impact factors of the SCB bridges depending on the speed.

The analysis focus on service velocities at which forced resonances in the BTT system may occur, commonly called the critical/resonant service velocities (the static pressures of moving wheel sets induce the cyclic excitation of the bridge). The resonant processes may be interfered/amplified by several factors specific to the BTT system, i.e. fast-varying configuration, potential micro separations and re-contacts of moving wheel sets, limited number of moving rail-vehicles, structural complexity, random track irregularities. This study presents the comparison of impact factors for track irregularities TI4, TI5 of five bridges from SCB (the series-of-types of steel-concrete bridges).

Table 2. Values of impact factors for BTT systems (SCB 15-27) with track irregularities TI4 and TI5

\begin{tabular}{|c|c|c|c|c|c|}
\hline SCB & {$[\mathrm{km} / \mathrm{h}]$} & $\begin{array}{c}\varphi_{w}(0.5 \mathrm{~L}) \\
\text { for TI4 }\end{array}$ & $\begin{array}{c}\varphi_{w}(0.5 \mathrm{~L}) \\
\text { for TI5 }\end{array}$ & $\begin{array}{c}\varphi_{\sigma}(0.5 \mathrm{~L}) \\
\text { for TI4 }\end{array}$ & $\begin{array}{c}\varphi_{\sigma}(0.5 \mathrm{~L}) \\
\text { for TI4 }\end{array}$ \\
\hline \multicolumn{6}{|c|}{ SCB-15 } \\
\hline$v_{11}$ & 180 & $\mathbf{4 , 9}$ & 4,2 & $\mathbf{5 , 6}$ & 4,6 \\
\hline$v_{21}$ & 270 & 3,7 & 3,2 & 4,4 & 3,7 \\
\hline$v_{\text {max }}$ & 300 & 2,5 & 2,2 & 3,1 & 2,6 \\
\hline \multicolumn{7}{|c|}{ SCB-18 } \\
\hline$v_{11}$ & 149 & 2,6 & 2,3 & 2,8 & 2,6 \\
\hline$v_{21}$ & 225 & 1,9 & $\mathbf{1 , 4}$ & 2,5 & 1,8 \\
\hline$v_{\text {max }}$ & 300 & 2,3 & 2,1 & 3,4 & 2,9 \\
\hline \multicolumn{7}{|c|}{ SCB-21 } \\
\hline$v_{11}$ & 135 & 1,6 & 1,6 & 1,9 & 1,6 \\
\hline$v_{21}$ & 203 & 2,3 & 2,3 & 2,8 & 2,4 \\
\hline$v_{\text {max }}$ & 300 & 2,5 & 2,5 & 3,6 & 2,8 \\
\hline \multicolumn{7}{|c|}{ SCB-24 } \\
\hline$v_{11}$ & 123 & 2,1 & 2,1 & 2,4 & 2,2 \\
\hline$v_{21}$ & 185 & 2,4 & 2,4 & 3,0 & 2,6 \\
\hline$v_{\text {max }}$ & 300 & 2,7 & 2,7 & 3,7 & 3,3 \\
\hline$v_{11}$ & 114 & 1,5 & 1,5 & 1,7 & 1,4 \\
\hline$v_{21}$ & 171 & 2,0 & 2,0 & 2,6 & 2,2 \\
\hline$v_{\text {max }}$ & 300 & 2,8 & 2,8 & 3,9 & 3,6 \\
\hline
\end{tabular}




\section{Conclusions}

The study focuses on establishing a dependence between the impact factors and the bridge's span or the impact factors and the train's velocity. Based on the above analysis, the following main conclusions were made:

- The impact factors in the longitudinal normal stress in the bottom fibres of main steel beams $\varphi_{\sigma}(0.5 L)$, as well as the impact factors in the vertical deflection $\varphi_{w}(0.5 L)$ do not depend on a bridge span for SCB 18-27, except for the maximum speed $v_{\max }=$ $300 \mathrm{~km} / \mathrm{h}$ for which the longest bridge has the highest values.

- As the train speed increases, the coefficients $\varphi_{w}(0.5 L), \varphi_{\sigma}(0.5 L)$ increase - it can be some kind of function for SCB 18-27.

- There is no significant difference in impact factors of the vertical deflection in the midspan $\varphi_{w}(0.5 L)$ depending on the rails irregularities in longer bridges (SCB 21-27). However the impact factors in the longitudinal normal stress in the bottom fibres of main steel beams at the midspan $\varphi_{\sigma}(0.5 \mathrm{~L})$ are greater with larger track irregularities.

- The shortest bridge span (SCB-15) and the resonance speed $v_{31}=180 \mathrm{~km} / \mathrm{h}$ has the values of the impact factors $\varphi_{w}(0.5 L), \varphi_{\sigma}(0.5 L)$ much higher than other SCB bridges.

- The object of the shortest span (SCB-15) presents the least favorably with the whole series of theoretical spans length from $15 \mathrm{~m}$ to $27 \mathrm{~m}$ in the above analysis. Moreover, similar results were obtained in studies performed on other criteria, e.g. the traffic safety condition or the passenger comfort condition (see Podworna [18]). The results confirm Rocha's theses: "Short span railway bridges,..., have been reported as problematic ..." [19].

\section{References}

1. L. Fryba, Dynamics of Railway Bridges (Academia, Praha 1996)

2. L. Fryba, A rough assessment of railway bridges for high speed trains, Engineering Structures, 23, 548 - 556 (2001)

3. L. Xu, W. Zhai, J. Gao, A probabilistic model for track random irregularities in vehicle/track coupled dynamics, Applied Mathematical Modelling 51, 145-158 (2017).

4. Y.S. Wu, Y.B. Yang, Steady-state response and riding comfort of trains moving over a series of simply supported bridges, Engineering Structures 25, 251-265 (2003)

5. N. Zhang, H. Xia, W. Guo, Vehicle-bridge interaction analysis under high-speed trains, Journal of Sound and Vibration 309, 407-425 (2008)

6. D. Mu, D.H. Choi, Dynamic responses of a continuous beam railway bridge under moving high speed train with random track irregularity, International Journal of Steel Structures 14(4), 797-810 (2014)

7. L. Xu, W. Zhai, Stochastic analysis model for vehicle-track coupled systems subject to earthquakes and track random irregularities, Journal of Sound and Vibration 407, 209-225 (2017)

8. F.T.K. Au, J.J.Wang, Y.K.Cheung, Impact study of cable stayed railway bridges with random rail irregularities, Engineering Structures 24, 529 - 541 (2002)

9. J. Ning, J. Lin, B. Zhang, Time-frequency processing of track irregularities in highspeed train, Mechanical Systems and Signal Processing 66-67, 339-348 (2016)

10. M.-K. Song, H.-C. Noh, C.-K. Choi, A new three dimensional finite element analysis model of high-speed train - bridge interactions, Engineering Structures 25, 1611 $1626(2003)$ 
11. A. Wiriyachai. K. H. Chu, V. K. Gang, Bridge impact due to wheel and track irregularities. ASCE Journal of Engineering. Mechanics 108(4), 648-666 (1982)

12. X. Lei. N.-A. Noda. Analyses of dynamic response of vehicle and track coupling system with random irregularity of track vertical profile, Journal of Sound and Vibration 258(1), 147-165 (2002).

13. Z. Wanming, W. Shaolin, Z. Nan,G. Mangmang, X. He, C. Chengbiao, Z. Chunfa, High-speed train-track-bridge dynamic interactions - Part II: experimental validation and engineering application, International Journal of Rail Transportation 1(1-2), 25-41, (2013)

14. M. Brunettia, J. Ciambellaa, L. Evangelistab, E. Lofranoa, A. Paolonea, A. Vittozzi, Experimental results in damping evaluation of a high-speed railway bridge, Procedia Engineering 199, 3015-3020 (2017)

15. M. Podwórna, M. Klasztorny, Vertical vibrations of composite bridge / track structure / high-speed train system. Part 1: Series-of-types of steel-concrete bridges, Bulletin of the Polish Academy of Science Technical Sciences 62(1), 165-179 (2014)

16. M. Podwórna, M. Klasztorny, Vertical vibrations of composite bridge / track structure / high-speed train system. Part 2: Physical and mathematical modelling, Bulletin of the Polish Academy of Science Technical Sciences 62(1), 181-196 (2014)

17. S.Z. Meymand, A. Keylin, M. Ahmadian, A survey of wheel-rail contact models for rail vehicles, Vehicle System Dynamics 54(3), 386-428 (2016)

18. M. Podwórna, Dynamic response of steel-concrete composite bridges loaded by highspeed train, Structural Engineering and Mechanics 62(2), 179-196 (2017)

19. J.M. Rocha, A.A. Henriques, R. Calçada, Probabilistic safety assessment of a short span high-speed railway bridge, Engineering Structures 71, 99-111 (2014) 